\title{
Decrecimiento: 10 preguntas para comprenderlo y debatirlo Denise Bayon, Fabbrice Filpo y François Schneider
}

\author{
El Viejo Topo, Mataró, España, 2012, 240 págs. \\ Fernando Tula Molina \\ Universidad Nacional de Quilmes - Conicet - Anpcyt, Buenos Aires, Argentina. \\ Email: ftulamolina@gmail.com
}

A la pregunta sobre ¿qué es el decrecimiento? los autores responderán que no hay una respuesta conceptual precisa, en tanto no se trata de una teoría sino del cuestionamiento sobre el estado de la democracia en nuestras sociedades contemporáneas; lo que dicen es, más bien, que se trata de una palabra-obús que busca "romper el consenso y el imaginario consumista", una denuncia de la falsa libertad que promueve la felicidad conforme de la publicidad. En este sentido, la critica se dirige menos hacia los términos que a la denuncia del "tiempo de consumo" como un falso tiempo libre, un tiempo alienado que habría que procurar disminuir en aras de la emancipación. Se parte de un diagnóstico severo, pero realista, sobre la degradación de los ecosistemas, de las identidades locales y de sus prácticas, en manos de la expansión de la actividad industrial motorizada por el diseño de productos obsoletos y la exacerbación publicitaria, siendo ambos los principales factores que dan forma continuada a la actual cultura de lo descartable. Así las cosas, el diagnóstico es que la dinámica de las sociedades desarrolladas quedó atrapada en el cerrado círculo de la movilidad transnacional de las empresas en procura de una rentabilidad y un afán de lucro sin límites. Efectivamente, como ya señalara A. Gorz (1923-2007), "la racionalidad económica sólo sabe del más y del menos, pero no de lo suficiente”. Si el crecimiento económico ha sido el principal agente dinámico de los últimos 200 años, también ha incurrido en constantes excesos de sobreexplotación (natural y humana), la cual sólo ha conocido la medida de la rentabilidad. Sobran los datos, pero baste mencionar los dos siguientes: el informe de referencia Living Beyond our means (2004), encomendado por la ONU y elaborado por más de 1500 científicos señala que $60 \%$ de los ecosistemas ya están degradados o explotados de modo no renovable; por otra parte la FAO observa que de continuar con el actual régimen de pesca se extinguirán totalmente los peces y moluscos para 2050.

¿Mero alarmismo ecológico? Se trata de mucho más que eso, pero la característica distintiva del movimiento decrecentista es el énfasis en que la crisis actual no es una crisis de escasez, sino de exceso. En mi opinión esto 
queda muy bien captado en las palabras de Marina Silva (Ex Ministra de Medio Ambiente y candidata a la presidencia de Brasil): "La crisis actual no es de falta y sí de exceso. Exceso de emisiones de carbono, de consumo de energía, de consumo de bienes y productos y de lucros, principalmente en los países desarrollados y en las clases sociales más favorecidas”" ${ }^{1}$. Es sólo a partir de tomar conciencia de que estamos excedidos que tiene sentido desear menos. Pero no es posible desear menos sin un cambio de mirada y del sentido de nuestras prácticas cotidianas. Esto es lo que vuelve al decrecimiento un movimiento radical, dado que ataca "el corazón del modo de vida mercantil-industrial” (p.60), bajo el slogan aparentemente ingenuo de "consumir menos para vivir mejor"; se trata de un replanteamiento radical del sistema de necesidades que está más allá de la polémica capialismosocialismo. En definitiva, el término "de-crecimiento" reúne a quienes consideran deseable reducir de manera duradera "la dimensión física del sistema económico" (p.21).

El principal objetivo de la crítica, será entonces, la "concepción burguesa de la riqueza” mostrando cómo las sociedades de trabajo y crecimiento fueron impulsadas por el capitalismo hacia una "valoración constante de la riqueza privada" (p.34). El punto es que la riqueza privada atenta contra la emancipación colectiva al "transformar en dinero toda materia y toda práctica social, quitándole toda posibilidad de crear nuevas instituciones” (p.34). En términos teóricos, parten de la crítica radical de Ivan Illich (1926-2002), la cual en mi opinión está aún vigente y pendiente de respuesta, aunque para muchos resulte tan inaudible como lo son las propuestas decrecentistas. Illich planteaba la necesidad de una reforma institucional radical, dado que las instituciones de la sociedad industrial, la educación obligatoria y la profesionalización, han superado los "umbrales de convivencia pacífica”. A grandes rasgos, Illich señalaba dos grandes umbrales: 1) Cuando una actividad social se confía a especialistas (pe. salud a los médicos); esto necesariamente crea dependencia; 2) Cuando se jerarquiza el acceso a un servicio (bajo el argumento de falta de recursos); esto crea escasez. Es decir, el planteo a partir de la estructura de una sociedad convivencial considera superficial la cuestión sobre la propiedad de los medios de producción, y cuestiona la propia lógica de la estructura productivista.

Por este motivo, los partidarios del decrecimiento prefieren verse como “objetores del crecimiento". Desde esta mirada, el marxismo fracasa "cuando la clase obrera se integra a los valores de enriquecimiento y consumo” (p.54); el sindicalismo reproduce el capitalismo actual al considerar al trabajo como principal fuente de riqueza, y el ambientalismo se limita a cuestionar la planificación territorial, pero no los propios "valores del capitalismo". Tampoco se trata otro movimiento contra-cultural que continúa abrevando en los sucesos de 1968. En este sentido, siguiendo al sociólogo L. Boltanski consideran que aquellas banderas de imaginación y emancipación fueron "recuperadas por el nuevo espíritu del capitalismo en nombre de la productividad”. Es aquí donde está tal vez la mayor novedad y radicalidad del decrecimiento: su posicionamiento es en contra del "creci- 
miento verde” y del “desarrollo sustentable”; desde su óptica no hay combinación posible de “aumento de PBI y aumento de calidad de vida” (p.73). En este sentido, demandan una renovación radical del movimiento ecologistas de modo que se posicione en contra tanto de la modernización ecológica como del capitalismo verde.

Justamente por su radicalidad es que considero necesario aclarar el sentido con el que son utilizados los principales conceptos:

Desarrollo sustentable: Los autores se encargan de mostrar que el concepto de “desarrollo sustentable” ha sido vaciado de significado, justamente para que las estructuras industriales puedan garantizar su rentabilidad atando la vida al consumo, sea o no verde; la industria se reinventa. Esto se volvió patente en la cumbre de Johannesburgo de (2002) la cual, a diferencia de la de Río (1992) donde se reunieron los Ministros de Medio Ambiente, fue celebrada por Ministros de Economía y de Relaciones Exteriores. No menos sugestivo es el hecho que de modo habitual los libros sobre desarrollo sustentable se encuentren catalogados bajo “economía” y no bajo “ecología”. En realidad, el desarrollo sustentable constituye una “apología del desarrollo existente”, la cual conduce al conformismo y la desmovilización.

Desarrollado - Subdesarrollado: Es necesario salir de la dicotomía primitivo-moderno, principal reacción de quienes siente amenazadas sus aspiraciones de crecimiento. De lo que se trata es de entrar en la conciencia de nuestra crisis actual y reconocer la necesidad de "salir del mal desarrollo” (p.100) y procurar retomar las proporciones en las actividades sociales que tiendan más hacia la convivencia, que hacia el crecimiento.

Democracia: ¿Es una hazaña pisar la Luna cuando no garantizamos la integridad de nuestro hábitat? ¿Destinamos dinero a despejar nuestra curiosidad sobre el Bosón de Higgs (esperando también aumentar nuestra capacidad de control de la naturaleza, lo cual justificaría los multimillonarios recursos destinados a la construcción de un gigantesco acelerador), o fomentamos la agricultura biológica que podría administrar mejor los recursos en un ambiente degradado? Sin duda que estas preguntas tiene respuestas múltiples; la pregunta central es ¿dónde está la democracia de las decisiones tomadas por la expertise? Esta pregunta no es menor, sobre todo en los días en que escribo y en el que el sistema Prism ha causado conflictos diplomáticos, sólo justificados en nombre de la seguridad de EEUU. También en estos días, Adolfo Pérez Esquivel hizo circular una carta -poco recogida en los medios- en la que se pregunta frente al hecho de que la Argentina se haya sometido para el contrato entre las petroleras YPF y Chevron ante un tribunal de EEUU: "si Chevron nos contamina e incumple el contrato, ¿además tendremos que indemnizarla? ¿por qué se tratará a libro cerrado en la legislatura provincial? ¿por qué no se consultó a los pueblos que habitan la zona, como dice la normativa internacional? Si YPF volvió a ser de los argentinos, ¿por qué hay cláusulas reservadas, que nadie puede conocer?". 
Productividad: El crecimiento económico "ya no produce progreso y centenares de millones de personas mueren de hambre” (p.125). La competitividades causa de degradación de los ecosistemas y disminución de expectativa de vida (p.156). La correlación de esperanza de vida/PBI “desaparece luego de los U\$ 18000 anuales; la relación no es lineal, lo que explica que una país como EEUU con un ingreso promedio de U\$ 40000 tenga una expectativa de vida semejante a la de Ecuador con un ingreso 10 veces menor (p.151). En este sentido, la salida del sistema de necesidades industriales se ve como “emancipación”.

Empleo: Se afirma que "sólo un crecimiento duradero hará volver el empleo" (p.161), pero esto es una ilusión de los economistas bajo la idea de “transferencia”. Entre 1949 y 2008 la población activa en Francia aumentó 48\%, pero la tasa de desempleo se multiplicó por 10; en España entre 1971 y 2009 el PBI se multiplicó por 3, mientras que la población activa sólo lo hizo por 1,5. La única correlación más allá de las promesas es que "el aumento del PBI y el aumento del desempleo y del empleo precario fueron a la par” (p.164). Por otra parte, el uso de las Técnicas Numéricas de Información y Control (TNIC) aumentaron la competitividad "a costa de una presión insoportable sobre los trabajadores” (p.173), y se artificializó el mundo en detrimento del trabajo vivo (p.176). En definitiva, "la destrucción del empleo es el resultado directo, lógico y esperable del crecimiento económico" (p.176).

Tecnología: Se reactualizan las críticas de Illich a la eficiencia de los medios de transporte de alta tecnología como el TGV; al ser más caros, los pobres precisan trabajar más para pagarlos, por lo que para ellos "pierde velocidad”, y de modo general se fomenta la desigualdad (sería más democrático invertir en TER, tren de cercanías). En realidad sus críticas son todavía más radicales que las de Illich y Gorz, en tanto ellos no atacaron en sí la tecnología, sino sólo su lógica industrial. Por el contrario, un punto central de la crítica decrecentista es que la tecnología "no cuestiona el estilo de vida moderno" e instala "valores autoritarios y tecnocráticos" (p.40), por lo que nos alejan de las soluciones. En una economía de acumulación de valor monetario, "no es posible que la técnica garantice a la vez ecología, democracia y aumento de PBI (p.131). Las soluciones tecnológicas, como los autos "high tech" de bajo consumo, sólo son posibles para los Estados “con alto grado de capital y producción” (p.189).

PBI: Ningún país “moderno” tiene una huella ecológica débil. Las crisis económicas y burbujas se producen porque cuando el capital se sobreacumula, ya no encuentra actividad suficientemente rentable para valorizarse. La medición del crecimiento a través del PBI implica una falsa contabilidad, basada en la idea también falsa de que el crecimiento mejora el bienestar de todo el mundo (p.29). Es necesario cambiarlo por otros, y esto ya ha comenzado, como las mediciones basadas en el índice de bienestar duradero (H. Daly / J. Cobb), el Índice de Bienestar Sostenible (Amigos de la Tierra) o el Índice de Progreso Genuino (New Economic Foundation) (p.149). 
Estado: Aquí es donde aparecen las mayores divergencias. Pueden distinguirse tres vertientes: 1) Libertaria: considera deslegitimadas todas las mediaciones políticas; 2) Culturalista: enfatiza que el problema son los valores que reproducen nuestras instituciones y que aboga por su necesaria transformación radical y disminución de su peso (S. Latouche); y 3) Institucionalista: cree en la posibilidad de un republicanismo de buena fe que aplique ecotasas no simbólicas y determine un techo para la riqueza (V. Cheynet, candidato a elecciones legislativas de Francia, 2007). El punto que los une es la conciencia sobre la necesidad de disminuir los intercambios comerciales, y aumentar las redes de ayuda mutua y el tiempo verdaderamente libre para "experimentar otras lógicas” (p.189). Se trata de reconstruir, reencontrar, las “culturas desvastadas por la globalización” (p.195).

Hechas estas aclaraciones puede considerarse al decrecimiento como algo más que un slogan para neutralizar la jerga economicista y "rediseñar una política del post-desarrollo" (p.202). En mi opinión este "algo más” consiste en los dos elementos siguientes:

1) Contra el individualismo, la búsqueda de un "dominio colectivo sobre el propio destino”; en la actualidad pequeñas causas tienen grandes efectos que abarcan a todos por igual; se pierde la distinción entre lo "tuyo y lo mío" frente a la actual crisis ecológica; se vuelve necesario reinsertarse en los ciclos naturales, entendidos como "una trama compleja tejida por microfuerzas evolutivas interconectadas” (p.103). Hay un valor intrínseco, no monetario, en la naturaleza (G. Roegen / H. T. Odum).

2) La idea general sobre los beneficios de utilizar circuitos más cortos. Esto implica un cambio de rumbo en nuestro estilo de vida basado en globalizar los desplazamientos y las posibilidades. Se vuelve necesario abandonar la "cowboy economy" y pasar a una verdadera administración de los recursos frente al agotamiento, más cercana a una "spaceship economy” (p.39).

En cualquier caso los objetores al crecimiento también hacen propuestas concretas. Las principales fueron recogidas en el encuentro de Barcelona (2010): promoción de monedas locales sin interés, semana laboral de 3 días, moratoria sobre mega-emprendimientos, reducción de la publicidad, limitación del acceso a los recursos del subsuelo, reutilización de casas vacías, ingreso básico incondicional, ingreso máximo, innovación frugal. Se trata de generar prácticas de convivencia que superen nuestras actuales prácticas de consumo. Se busca rescatar la deliberación directa sobre nuestras condiciones de vida y la exploración consciente de la autolimitación, como fueron practicadas por las tradiciones populares, o elaboradas intelectualmente bajo "la norma de lo suficiente” (A. Gorz).

No sólo está la pobreza, sino la propia democracia en juego. El avance de los agro-combustibles en el mundo entero está radicalizando una lucha entre hambrientos y automovilistas y aumentando las desigualdades. 
Un ejemplo de la interdependencia de factores puede verse en el negocio de los combustibles, el cual es indudablemente mayor al de la cerveza. Uno de los países más “desarrollados”, Alemania, tiene el 16\% de su superficie destinadas a agro-carburantes; es decir, tierra y alimentos destinados a los automóviles; por la disminución del área de cultivo destinada a la cebada, en 2006 el precio de la malta se duplicó. El constantemente promocionado crecimiento tomando a la industria automotriz como un factor de peso, no sólo excede la capacidad de carga de las ciudades, sino también la capacidad de carga de los ecosistemas, condenándonos a la escasez. Y todo para alimentar la misma agroindustria, basada en más petróleo (fertilizantes y pesticidas); es decir, los mismos ganadores y perdedores de nuestro actual modelo de crecimiento. Una industria de un enorme despilfarro energético que sólo contribuye al empeoramiento de la calidad alimentaria. La relación de unidades energéticas utilizadas y las unidades alimenticias producidas es 60\% superior a la agricultura biológica ¿Por qué preferirla entonces? ¿Por qué no democratizar las decisiones que involucran la extracción de los recursos? No basta con gravar a los ricos, ya que esto supone la hipótesis falsa "de que todos podrían ser igualmente ricos" (p.200)... Se trata de plantearse seriamente si la reducción de nuestros consumos globales, y la construcción de sociedades de postdesarrollo, suponen una pérdida o una recuperación de nuestra dignidad. 


\section{Nota}

${ }^{1}$ Rifkin J., A Terceira Revoluçao Industrial: cómo el poder lateral está transformando a energia, a economia e o mundo, M.Books Brasil, San Pablo, p. 14. 